\title{
Mortality due to cirrhosis and liver cancer in the United States, 1999-2016: observational study
}

\author{
Elliot B Tapper, ${ }^{1,2}$ Neehar D Parikh ${ }^{1,2}$
}

${ }^{1}$ Division of Gastroenterology and Hepatology, University of Michigan, MI, USA

${ }^{2}$ Gastroenterology Section, VA Ann Arbor Healthcare System, Ann Arbor, MI, USA

Correspondence to: EB Tapper 3912 Taubman, SPC 5362 1500 E Medical Center Dr, Ann Arbor, MI 48109, USA etapper@umich.edu (@ebtapper on Twitter) Additional material is published online only. To view please visit the journal online.

Cite this as: BMJ 2018;362:k2817 http://dx.doi.org/10.1136/bmj.k2817 Accepted: 11 June 2018

\author{
ABSTRACT \\ OBJECTIVE \\ To describe liver disease related mortality in the \\ United States during 1999-2016 by age group, sex, \\ race, cause of liver disease, and geographic region. \\ DESIGN \\ Observational cohort study. \\ SETTING \\ Death certificate data from the Vital Statistics \\ Cooperative, and population data from the US Census \\ Bureau compiled by the Center for Disease Control \\ and Prevention's Wide-ranging Online Data for \\ Epidemiologic Research (1999-2016).

\section{PARTICIPANTS} \\ US residents.
}

\section{MAIN OUTCOME MEASURE}

Deaths from cirrhosis and hepatocellular carcinoma, with trends evaluated using joinpoint regression.

RESULTS

From 1999 to 2016 in the US annual deaths from cirrhosis increased by $65 \%$, to 34174 , while annual deaths from hepatocellular carcinoma doubled to 11073 . Only one subgroup-Asians and Pacific Islanders-experienced an improvement in mortality from hepatocellular carcinoma: the death rate decreased by $2.7 \%$ (95\% confidence interval $2.2 \%$ to $3.3 \%, \mathrm{P}<0.001)$ per year. Annual increases in cirrhosis related mortality were most pronounced for Native Americans (designated as "American Indians" in the census database) $(4.0 \%, 2.2 \%$ to $5.7 \%, \mathrm{P}=0.002)$. The age adjusted death rate due to hepatocellular carcinoma increased annually by $2.1 \%$ (1.9\% to $2.3 \%$, P 0.001$)$; deaths due to cirrhosis began increasing in 2009 through 2016 by $3.4 \%$ (3.1\% to $3.8 \%$, P<0.001). During 2009-16 people aged 25-34 years experienced the highest average annual increase in cirrhosis related mortality $(10.5 \%, 8.9 \%$ to $12.2 \%$, P<0.001), driven entirely by alcohol related liver disease. During this period, mortality due to peritonitis and sepsis in the setting of cirrhosis increased substantially, with

\section{WHAT IS ALREADY KNOWN ON THIS TOPIC}

Cirrhosis is a morbid condition that is increasing in prevalence

Although hepatitis C viral infection is being eradicated, the burden of alcoholic liver disease and non-alcoholic fatty liver disease is increasing

\section{WHAT THIS STUDY ADDS}

Mortality due to cirrhosis has been increasing in the USA since 2009

People aged 25-34 have experienced the greatest relative increase in mortality, driven by deaths due to alcoholic cirrhosis

During 2009-16 white Americans, Native Americans, and Hispanic Americans experienced the greatest increase in deaths from cirrhosis; such mortality is improving in Maryland but worst in Kentucky, New Mexico, and Arkansas respective annual increases of $6.1 \%$ (3.9\% to $8.2 \%)$ and $7.1 \%$ (6.1\% to $8.4 \%)$. Only one state, Maryland, showed improvements in mortality $(-1.2 \%,-1.7 \%$ to $-0.7 \%$ per year), while many, concentrated in the south and west, observed disproportionate annual increases: Kentucky 6.8\% (5.1\% to 8.5\%), New Mexico 6.0\% (4.1\% to 7.9\%), Arkansas 5.7\% (3.9\% to $7.6 \%$ ), Indiana $5.0 \%$ (3.8\% to $6.1 \%$ ), and Alabama $5.0 \%(3.2 \%$ to $6.8 \%)$. No state showed improvements in hepatocellular carcinoma related mortality, while Arizona (5.1\%, 3.7\% to 6.5\%) and Kansas (4.3\%, $2.8 \%$ to $5.8 \%$ ) experienced the most severe annual increases.

\section{CONCLUSIONS}

Mortality due to cirrhosis has been increasing in the US since 2009. Driven by deaths due to alcoholic cirrhosis, people aged 25-34 have experienced the greatest relative increase in mortality. White Americans, Native Americans, and Hispanic Americans experienced the greatest increase in deaths from cirrhosis. Mortality due to cirrhosis is improving in Maryland but worst in Kentucky, New Mexico, and Arkansas. The rapid increase in death rates among young people due to alcohol highlight new challenges for optimal care of patients with preventable liver disease.

\section{Introduction}

Cirrhosis, the end result for most chronic liver diseases, ${ }^{1}$ is characterized by fatal, resource intensive complications. These include hepatocellular carcinoma, hepatic encephalopathy, gastrointestinal hemorrhage, infections, and renal failure. Cirrhosis and hepatocellular carcinoma carry personal, social, and financial burdens for patients, their families, and society. ${ }^{2-4}$ In the past decade in the USA this problem has been compounded by a doubling in the prevalence of cirrhosis. ${ }^{56}$ Although hepatitis $\mathrm{C}$ virus, a major cause of cirrhosis, could be eradicated given the recent advent of widely available and highly effective antiviral therapy, this trend is likely to continue. ${ }^{7}$ Deaths due to cirrhosis are expected to triple by $2030 .^{8}$ Projected increases in the burden of cirrhosis are thought to be driven primarily by the increasing prevalence of alcoholic liver disease and non-alcoholic fatty liver disease. $^{9-11}$ The incidence and impact of cirrhosis related complications is uneven across the USA, with substantial geographic and demographic variability. ${ }^{12}$

Prevention and early management of cirrhosis is cost effective. ${ }^{13-15}$ However, nationally representative data to guide the optimal allocation of resources and preventive efforts are limited, particularly regarding differential mortality by demographic subgroups or US regions. ${ }^{16}$ Understanding the trends in cirrhosis related mortality in specific subgroups may clarify the differential impact and targets for improvement 
of cirrhosis related outcomes. Herein, we describe the temporal trends in liver disease related deaths in US adults using the Center for Disease Control and Prevention's Wide-ranging Online Data for Epidemiologic Research (CDC WONDER) platform.

\section{Methods}

Data were obtained from the CDC WONDER platform (see supplemental material for more details). ${ }^{17}$ Our primary aim was to describe temporal trends in death rates attributable to cirrhosis (ICD-10 (international classification of diseases, 10th revision) codes K70.3, $\mathrm{K} 74.5$, and K74.6) and hepatocellular carcinoma (C22.0) as the primary or underlying cause of death for adults in the USA. We adjusted rates for age-that is, age specific mortality was weighted according to the age distribution in a standard year (2000). ${ }^{18}$ We also sought to describe how these trends differed based on demographic subgroups; age, sex, race (Asian or Pacific Islander, Native American (designated as "American Indian" in the census database) or Alaska Native, black or African American, and white American), Hispanic ethnicity, and geographic area of residence. We also aimed to describe trends in causes of death related to specific complications associated with cirrhosis. Specifically, we examined death due to gastrointestinal hemorrhage (ICD-10 K25-K28, K92.0-K92.2, I85.0), peritonitis (K65), sepsis (A41), hepatorenal syndrome (K76.7), and traumas (V01-Y89). Given the association between nonalcoholic fatty liver disease and complications of the metabolic syndrome such as cerebrovascular disease and ischemic heart disease (I20-I25, I60-I69), ${ }^{19}$ we evaluated trends in mortality due to cirrhosis comorbid with these conditions. We also compared trends in deaths due to alcohol use disorder (F10).

To test for unmeasured secular trends, we compared all findings with death rates due to causes other than cirrhosis. Specifically, we examined the trends in deaths due to infections (ICD-10 A00-B99), neoplasia (COO-C48, not including hepatocellular carcinoma, C22), cardiovascular disease (I00-I99), and respiratory disease (J00-J98). Finally, we assessed overall trends in several US states that were observed to have the greatest increase or highest death rates due to cirrhosis and hepatocellular carcinoma (eg, Arizona, New Mexico, and Wyoming).

We performed several sensitivity analyses. First we evaluated trends when the cause of death was labeled as any liver disease with or without cirrhosis (ICD-10 K70-K76). Next we evaluated trends when the death certificate included any mention of cirrhosis as a primary or contributory cause; a death certificate can have a primary or underlying cause and up to 20 contributing causes. Finally, we repeated the trend analysis that included age adjusted death rate estimates by standardizing rates to different years (2000, 2009, and 2010) and sex (men or women).

\section{Data analysis}

We then evaluated trends in death rates using the National Cancer Institute's Joinpoint program (version
4.6.0; http://surveillance.cancer.gov/joinpoint). This enabled us to identify if there were years in the study period where the rate of change in mortality was statistically significantly different. The program uses a piecewise linear regression approach to determine whether rates over time are best described by a straight line (0 joinpoints) or by multiple linear segments $(\geq 1$ joinpoints). ${ }^{20}{ }^{21}$ The software detects the joinpoints in the trends using a grid search method to observe the joinpoints at any point in the time trend, ${ }^{22}$ fitting a linear regression between consecutive joinpoints using the least squares approach. To simplify the model, we specified modeling procedures to keep a maximum of three joinpoints (changes in slope) with a minimum of three years for each segment. Using validated methods, we obtained the annual percentage change in death rates over each linear segment as well as the average annual percentage change with $95 \%$ confidence intervals during 1999-2016 for each model. ${ }^{2324}$ The annual percentage change was obtained using a Monte-Carlo permutation analysis. Given the uncertainty of each year's mortality (represented by the confidence intervals), this analytic approach fits a line through 4500 different samples of each year's rate in order to estimate the annual percentage change. The permutation test provides a $\mathrm{P}$ value reflecting the probability that the original sample based on the calculated mortality estimates was due to chance. The software selects a final model based on the minimum number of joinpoints (within the set limits) to explain the mortality trends. We adjusted $P$ values through a Bonferroni correction for multiple testing given the use of numerous analyses used to select the number of joinpoints. The average annual percentage change is a weighted average of the segmented annual percentage change over a specified interval, providing a valid summary statistic to compare rate changes across groups. We found one Joinpoint in the trends of cirrhosis mortality at 2009. To further understand demographic trends, we analyzed our data during 2009-16.

When comparing the trends in mortality due to cirrhosis with those of control conditions, we evaluated the differences using a test for parallelism. ${ }^{25}$ This test evaluates whether curves of differing absolute values are parallel over multiple (in this case 4500) permutations of each model.

\section{Patient and public involvement}

No patients were involved in setting the research question or the outcome measures, nor were they involved in developing plans for the design of the study. No patients were asked to advise on interpretation or writing up of results. There are no plans to disseminate the results of the research to study participants or the relevant patient community.

\section{Results}

\section{Burden of mortality due to liver disease}

During the study period, a total of 460760 deaths were attributed to cirrhosis (20661 in 1999 and 34174 in 2016) and 136442 to hepatocellular carcinoma (5112 in 1999 and 11073 in 2016) (table 1). Men 
had a higher burden of age adjusted mortality due to cirrhosis compared with women by a 2:1 ratio and a higher burden of mortality due to hepatocellular carcinoma by a nearly 4:1 ratio. The highest burden of age adjusted mortality due to cirrhosis was seen in Native Americans (25.8/100 000), followed by white Americans (12.7/100000). Age adjusted mortality due to hepatocellular carcinoma was highest in Asians and Pacific Islanders. Compared with non-Hispanic Americans, those of Hispanic ethnicity had relatively high age adjusted mortality from both cirrhosis (19.3 $v$ 11.5/100 000) and hepatocellular carcinoma (5.7 v $3.4 / 100000)$. Of the regions, the south and west had the highest age adjusted mortality from cirrhosis (13.5 and 13.3/100 000, respectively) and the west had the highest age adjusted mortality from hepatocellular carcinoma (4.2/100 000). In supplementary tables 1a and $1 \mathrm{~b}$ we provide death rates due to all liver disease codes and deaths where cirrhosis was noted in any of the up to 20 positions on the death certificate. While these sensitivity tests accounted for more deaths (742800 and 800344 , respectively), the trends were the same, with statistically parallel annual trends for each subgroup. In supplementary table 1c, we provide death rates for people with both cirrhosis and hepatocellular carcinoma recorded on the death certificate. Although the number of deaths are lower, the relative burden by subgroup is similar to that of hepatocellular carcinoma overall with the exception that Native Americans have a higher burden of hepatocellular carcinoma and cirrhosis.

\section{Demographic trends in mortality due to cirrhosis} and hepatocellular carcinoma

Cirrhosis-We evaluated trends in mortality from cirrhosis in demographic subgroups with several important findings (table 2). Firstly, there was an inflection point at 2009 where cirrhosis related mortality increased statistically significantly through to 2016. Several subgroups had statistically significant declines in cirrhosis related mortality from 1999 to 2008; however, these trends reversed in nearly every demographic subgroup, beginning in 2009. Secondly, although more men are dying from (or with) cirrhosis and hepatocellular carcinoma, both sexes experienced similar rates of increased mortality over time. Thirdly, white Americans and Native Americans had rapid increases in mortality from cirrhosis after 2009, with an average annual percentage change of 3.3\% (95\% confidence interval $8.0 \%$ to $3.7 \%)$ and $4.0 \%(2.2 \%$ to $5.7 \%$ ) compared with African Americans. Fourthly, non-Hispanic Americans experienced a slower increase in cirrhosis related mortality than Hispanic Americans. Fifthly, in recent years, the north east USA had the slowest increase $(1.6 \%, 1.1 \%$ to $2.1 \%)$, whereas the south had the fastest $(3.5 \%, 2.8 \%$ to $4.2 \%)$.

Hepatocellular carcinoma-The demographic trends in mortality from hepatocellular carcinoma are markedly different from those of cirrhosis. Firstly, overall, there was a $2.1 \%$ (95\% confidence interval $1.9 \%$ to $2.3 \%$ ) increase in mortality from hepatocellular carcinoma nationally over the study period. Secondly, women experienced a consistent increase in mortality from hepatocellular carcinoma, while for men hepatocellular carcinoma death rates slowed, beginning in 2011. Thirdly, Asian and Pacific Islanders were the only subgroup with an improvement in mortality from hepatocellular carcinoma, experiencing a consistent decrease of $2.7 \%$ (95\% confidence interval $2.2 \%$ to $3.3 \%$ ) per year. Thirdly, all US regions except for the north east experienced statistically significant increases in mortality from hepatocellular carcinoma over the study period.

\section{Age related trends in mortality from cirrhosis and} hepatocellular carcinoma

We performed several analyses to better delineate the populations affected by worsening trends in mortality

\begin{tabular}{|c|c|c|c|c|c|c|}
\hline \multirow[b]{2}{*}{ Demographic factors } & \multicolumn{3}{|l|}{ Cirrhosis } & \multicolumn{3}{|c|}{ Hepatocellular carcinoma } \\
\hline & No of deaths & $\begin{array}{l}\text { Crude rate } / 100000 \\
(95 \% \mathrm{Cl})\end{array}$ & $\begin{array}{l}\text { Age adjusted } / 100000 \\
(95 \% \mathrm{Cl})\end{array}$ & No of deaths & $\begin{array}{l}\text { Crude rate } / 100000 \\
(95 \% \mathrm{Cl})\end{array}$ & $\begin{array}{l}\text { Age adjusted } / 100000 \\
(95 \% \mathrm{Cl})\end{array}$ \\
\hline Overall & 460760 & $12.87(12.83$ to 12.91$)$ & $12.18(12.14$ to 12.21$)$ & 136442 & 3.81 (3.79 to 3.83$)$ & 3.55 (3.53 to 3.56$)$ \\
\hline \multicolumn{7}{|l|}{ Sex: } \\
\hline Women & 162599 & 8.75 (8.71 to 8.79$)$ & $8.02(7.98$ to 8.06$)$ & 31694 & $1.70(1.68$ to 1.71$)$ & $1.50(1.48$ to 1.51$)$ \\
\hline Men & 298161 & $17.31(17.25$ to 17.37$)$ & $16.82(16.76$ to 16.88$)$ & 105248 & $6.1(6.06$ to 6.14$)$ & $5.97(5.93$ to 6.01$)$ \\
\hline \multicolumn{7}{|l|}{ Race: } \\
\hline Native American & 9145 & 23.7 (23.21 to 24.18$)$ & 25.81 (25.26 to 26.37$)$ & 1386 & $3.6(3.41$ to 3.79$)$ & $4.72(4.46$ to 4.99$)$ \\
\hline Asian and Pacific Islander & 6687 & 3.59 (3.51 to 3.68$)$ & $4.45(4.34$ to 4.56$)$ & 11241 & $6.02(5.91$ to 6.13$)$ & $7.43(7.29$ to 7.57$)$ \\
\hline African American & 40598 & $9.43(9.33$ to 9.52$)$ & 9.71 (9.61 to 9.81$)$ & 21303 & $4.94(4.87$ to 5.00$)$ & $5.20(5.13$ to 5.27$)$ \\
\hline White & 404330 & $13.82(13.78$ to 13.86$)$ & $12.71(12.67$ to 12.75$)$ & 103012 & 3.51 (3.49 to 3.53$)$ & 3.15 (3.13 to 3.17$)$ \\
\hline Hispanic & 64001 & $14.18(14.07$ to 14.29$)$ & 19.27 (19.11 to 19.42$)$ & 17288 & $3.82(3.76$ to 3.88$)$ & $5.74(5.65$ to 5.83$)$ \\
\hline Non-Hispanic & 395128 & $12.63(12.59$ to 12.67$)$ & $11.51(11.47$ to 11.54$)$ & 119250 & 3.80 (3.78 to 3.82$)$ & 3.37 (3.35 to 3.39) \\
\hline \multicolumn{7}{|l|}{ Geographic region: } \\
\hline North east & 71388 & $10.65(10.58$ to 10.73$)$ & 9.81 (9.74 to 9.89$)$ & 23996 & 3.85 (3.8 to 3.90$)$ & 3.48 (3.43 to 3.52$)$ \\
\hline Midwest & 90958 & $11.60(11.52$ to 11.67$)$ & $10.78(10.71$ to 10.85$)$ & 24172 & 3.34 (3.30 to 3.38$)$ & $3.06(3.02$ to 3.10$)$ \\
\hline South & 187949 & $14.32(14.25$ to 14.38$)$ & $13.53(13.47$ to 13.6$)$ & 45105 & 3.75 (3.72 to 3.79$)$ & 3.49 (3.46 to 3.52$)$ \\
\hline West & 110465 & $13.58(13.5$ to 13.66$)$ & $13.33(13.25$ to 13.41$)$ & 32596 & $4.34(4.29$ to 4.38$)$ & $4.23(4.19$ to 4.28$)$ \\
\hline
\end{tabular}




\begin{tabular}{|c|c|c|}
\hline Years of similar trend (joinpoints) by variables & Annual percentage change $(95 \% \mathrm{Cl})$ & $P$ value \\
\hline \multicolumn{3}{|l|}{ Cirrhosis } \\
\hline \multicolumn{3}{|l|}{ Overall: } \\
\hline $1999-2008$ & $-0.5(-0.9$ to -0.1$)$ & 0.02 \\
\hline $2008-16$ & 3.4 (3.1 to 3.8$)$ & $<0.001$ \\
\hline \multicolumn{3}{|l|}{ Sex: } \\
\hline \multicolumn{3}{|l|}{ Women } \\
\hline $1999-2008$ & $-0.3(-0.8$ to 0.2$)$ & 0.2 \\
\hline $2008-16$ & $3.6(3.1$ to 4.2$)$ & $<0.001$ \\
\hline \multicolumn{3}{|l|}{ Men } \\
\hline 1999-2009 & $-0.7(-1.1$ to -0.3$)$ & 0.003 \\
\hline $2009-16$ & $2.6(2.1$ to 3.0$)$ & $<0.001$ \\
\hline \multicolumn{3}{|l|}{ Race: } \\
\hline \multicolumn{3}{|l|}{ Native American } \\
\hline $1999-2010$ & $-0.3(-1.2$ to 0.5$)$ & 0.4 \\
\hline $2010-16$ & $4.0(2.2$ to 5.7$)$ & 0.002 \\
\hline Asian and Pacific Islander & & 0.2 \\
\hline 1999-2016 & $0.3(-0.2$ to 0.7$)$ & \\
\hline \multicolumn{3}{|l|}{ African American } \\
\hline $1999-2008$ & $-3.6(-4.3$ to -3.9$)$ & $<0.001$ \\
\hline $2008-16$ & $1.7(0.9$ to 2.4$)$ & 0.003 \\
\hline \multicolumn{3}{|l|}{ White American } \\
\hline $1999-2008$ & $-0.1(-0.5$ to 0.3$)$ & 0.7 \\
\hline 2009-16 & $3.3(2.8$ to 3.7$)$ & $<0.001$ \\
\hline \multicolumn{3}{|l|}{ Hispanic American } \\
\hline 1999-2007 & $-1.7(-2.3$ to -1.0$)$ & $<0.001$ \\
\hline $2008-16$ & $1.3(0.8$ to 1.7$)$ & $<0.001$ \\
\hline \multicolumn{3}{|l|}{ Non-Hispanic American } \\
\hline $1999-2008$ & $-0.5(-0.9$ to -0.1$)$ & 0.02 \\
\hline $2009-16$ & $3.0(2.5$ to 3.4$)$ & $<0.001$ \\
\hline \multicolumn{3}{|l|}{ Region of residence: } \\
\hline \multicolumn{3}{|l|}{ North east } \\
\hline $1999-2007$ & $-2.2(-2.8$ to -1.6$)$ & $<0.001$ \\
\hline $2007-16$ & $1.6(1.1$ to 2.1$)$ & $<0.001$ \\
\hline \multicolumn{3}{|l|}{ Midwest } \\
\hline 1999-2008 & $-0.4(-0.7$ to -0.1$)$ & 0.01 \\
\hline $2008-16$ & $3.1(2.7$ to 3.4$)$ & $<0.001$ \\
\hline \multicolumn{3}{|l|}{ South } \\
\hline 1999-2009 & $-0.1(-0.6$ to 0.3$)$ & 0.4 \\
\hline $2009-16$ & 3.5 (2.8 to 4.2$)$ & $<0.001$ \\
\hline \multicolumn{3}{|l|}{ West } \\
\hline $1999-2008$ & $-0.1(-0.7$ to 0.6$)$ & 0.8 \\
\hline \multicolumn{3}{|l|}{ Hepatocellular carcinoma } \\
\hline \multicolumn{3}{|l|}{ Overall: } \\
\hline $1999-2016$ & 2.1 (1.9 to 2.3$)$ & $<0.001$ \\
\hline $2008-16$ & $3.0(2.3$ to 3.6$)$ & $<0.001$ \\
\hline Sex: & & \\
\hline Women & & \\
\hline $1999-2016$ & $1.3(1.9$ to 1.7$)$ & $<0.001$ \\
\hline Men & & \\
\hline $1999-2010$ & $2.6(2.1$ to 3.1$)$ & $<0.001$ \\
\hline $2010-16$ & $1.3(0.4$ to 2.3$)$ & 0.02 \\
\hline Race: & & \\
\hline Native American & & \\
\hline $1999-2016$ & 2.3 (1.1 to 3.5$)$ & 0.007 \\
\hline Asian and Pacific Islander & & \\
\hline $1999-2016$ & $-2.7(-3.3$ to -2.2$)$ & $<0.001$ \\
\hline African American & & \\
\hline $1999-2016$ & $2.2(1.7$ to 2.7$)$ & $<0.001$ \\
\hline White American & & \\
\hline
\end{tabular}




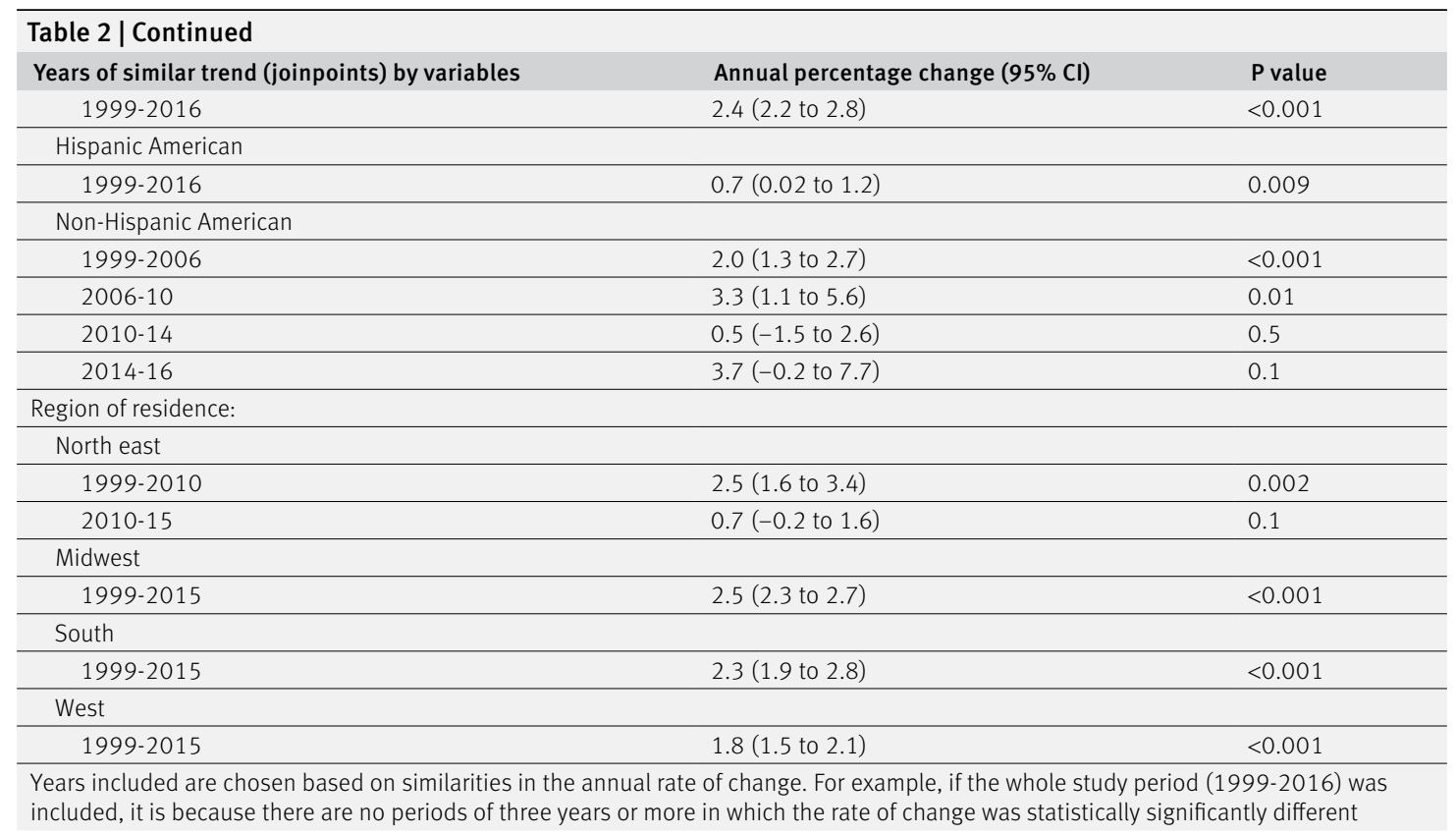

from cirrhosis during the period of worsening death rates (2009-16). Firstly, we examined changing death rates by age group (fig 1). Those aged 25-34 experienced the highest average annual percentage change in mortality from cirrhosis; 3.7\% (95\% confidence interval $2.4 \%$ to $5.1 \%)$ over the whole period and $10.5 \%$ (8.9\% to $12.2 \%$ ) during $2009-16$ (fig 1). White Americans and Native Americans experienced the most rapid increase in this age group. Increased death rates in the 25-34 age group were driven by alcoholic cirrhosis, where the average annual percentage change from 2009 to 2016 was $10.5 \%$ (95\% confidence interval $9.2 \%$ to $11.8 \%$ ). These findings are reinforced by parallel changes in mortality due to alcohol use disorders and all alcohol related liver diseases (fig 1). The proportion of all cause mortality varied by age group and race during 2009-16 (see supplemental tables 2a and 2b). Notably, by 2016, cirrhosis accounted for 6.3\% (up from 4.3\% in 2009) and $7.0 \%$ (up from $5.8 \%$ in 2009) of deaths for Native Americans aged 25-34 and 35 or more, respectively. Cirrhosis accounted for $1.4 \%$ (up from $0.9 \%$ in 2009) and $2.3 \%$ (up from $1.8 \%$ in 2009) of deaths for adults aged 25-34 and 35 or more, respectively. Hepatocellular carcinoma related mortality shows an opposite age relation; it has decreased in younger people ( $<55$ years) since 2009 and increased among those aged more than 55 from 2009 to 2016 (fig 1). In a sensitivity test, we evaluated patients with both hepatocellular carcinoma and cirrhosis recorded on the death certificate. A formal trend analysis of young people was not possible, as $80 \%$ of deaths due to cirrhosis-hepatocellular carcinoma occurred in those older than 55 years. Only 58 deaths were recorded for this combination of causes for people aged 25-34 years.

\section{Cause specific mortality trends}

Next, we sought to determine whether specific common causes of death in patients with cirrhosis changed over the study period. Supplementary table 3 depicts the time trends in comorbid causes of death for patients who died from cirrhosis. The average annual percentage change for cirrhosis related deaths due to peritonitis and sepsis increased statistically significantly $(1.5 \%, 95 \%$ confidence interval $0.2 \%$ to $2.8 \%$ and $3.7 \%, 3.2 \%$ to $4.0 \%$, respectively), while no significant changes were observed for comorbid upper gastrointestinal hemorrhage, hepatorenal syndrome, cerebrovascular and ischemic heart disease, and trauma. Since 2009, however, the mortality associated with each condition increased, except for trauma. Notably, from 2009 to 2016 the magnitude of increased mortality due to peritonitis and sepsis rose substantially, with respective average annual percentage changes of $6.1 \%$ (3.9\% to $8.2 \%$ ) and $7.1 \%$ (6.1\% to $8.4 \%)$. Most $(60 \%)$ of the 47290 patients with sepsis or peritonitis were aged 45-64. All age groups had increasing mortality, but the rate of change was not statistically parallel. For example, those aged 25-34 and 35-44 experienced sharp increases in sepsis or peritonitis related mortality, beginning in 2009; the average annual percentage change (2009-16) for these groups was $13.5 \%$ (95\% confidence interval $9.4 \%$ to $17.4 \%$ ) and $7.4 \%$ (4.3\% to $10.6 \%$ ). People aged 75 84 experienced a later joinpoint with an increase in mortality due to sepsis or peritonitis during 2013-16 (12.4\%, 3.8\% to $21.8 \%$ ), and people aged 85 years or more showed a linear increase during 1999-2016 of $3.3 \%(2.0 \%$ to $4.6 \%)$.

\section{State level variation in mortality}

We next examined geographic changes in cirrhosis and hepatocellular carcinoma related mortality since 2009. The fastest rise in cirrhosis and hepatocellular carcinoma related mortality occurred in the western and southern USA. In supplementary tables 4-5, we detail the state level changes in mortality from 2009 

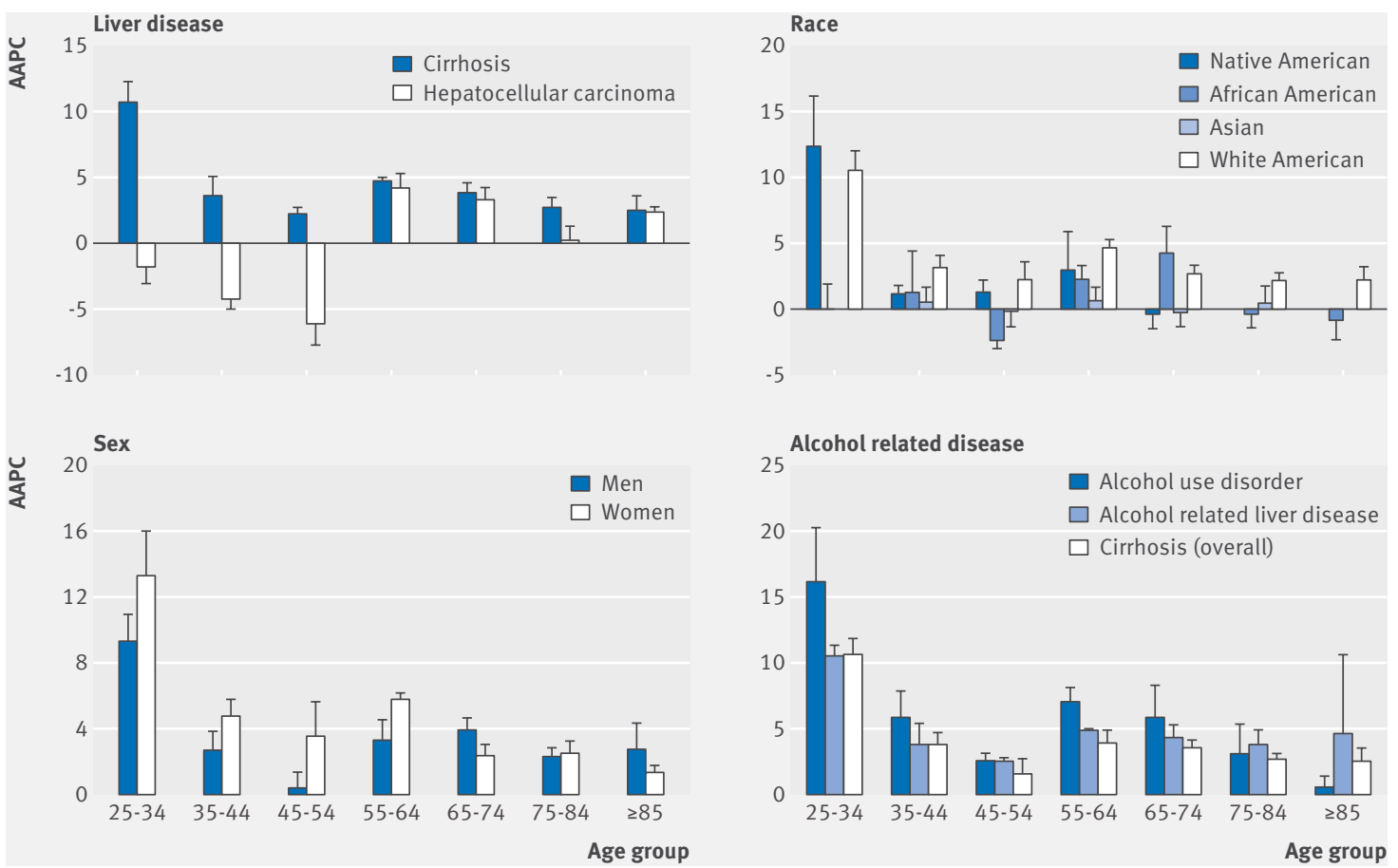

Fig 1 | Trends in mortality due to liver disease by age group in the USA, 2009-16. AAPC=average annual percentage change

to 2016; in a series of heat maps (fig 2) we show how the death rate due to cirrhosis and hepatocellular carcinoma has changed over time.

The states with the greatest average annual percentage change in cirrhosis related mortality were Kentucky $(6.8 \%, 5.1 \%$ to $8.5 \%)$, New Mexico $(6.0 \%, 4.1 \%$ to $7.9 \%)$, Arkansas $(5.7 \%, 3.9 \%$ to $7.6 \%)$, Indiana $(5.0 \%, 3.8 \%$ to $6.1 \%)$, and Alabama $(5.0 \%, 3.2 \%$ to $6.8 \%$ ) (fig 3). Maryland experienced a statistically significant annual decrease in cirrhosis related deaths $(-1.2 \%,-1.7 \%$ to $-0.7 \%)$.

No state experienced a statistically significantly decreasing mortality due to hepatocellular carcinoma (fig 3). Many of the same states with worsening cirrhosis related mortality also experienced worsening mortality from hepatocellular carcinoma (eg, Oregon, Iowa). However, some states experienced increased hepatocellular carcinoma related deaths out-of-sync with cirrhosis trends: Arizona (5.1\%, 3.7\% to 6.5\%), Kansas (4.3\%, 2.8\% to 5.8\%), Kentucky (4.0\%, 3.1\% to $5.0 \%)$, and Washington $(3.9 \%, 3.1 \%$ to $4.6 \%)$.

\section{State level variation in mortality due to alcohol related diseases}

The average annual percentage change for deaths due to alcoholic cirrhosis increased most rapidly in Louisiana (13.1\%, 7.7\% to $18.9 \%$ ), California (12.9\%, $6.7 \%$ to $19.5 \%)$, Kentucky $(12.8 \%, 9.8 \%$ to $15.8 \%$ ), Delaware $(9.8 \%, 5.1 \%$ to $14.7 \%)$, and New Mexico (9.3\%, 6.3\% to $12.4 \%$ ) (fig 4). Conversely, the District of Columbia and Maryland had the only improvements in mortality. None of the state level trends in deaths due to alcohol use disorder were statistically parallel with those of alcohol related cirrhosis (fig 4); however, many were qualitatively similar. Supplementary table 6 shows the age adjusted mortality and annual changes in mortality for alcohol use disorder for each state.

\section{Secular trends in non-cirrhotic death rates (1999- 2016)}

Age adjusted mortality uniformly decreased across the states, with the exception of Utah, where the average annual percentage change during 2009-16 was $0.6 \%(0.3 \%$ to $0.8 \%)$. Supplementary table 7 shows a sample of states, chosen for their statistically significant changes in cirrhosis related mortality. None of the statewide trends for all cause mortality were statistically parallel with those of cirrhosis or hepatocellular carcinoma. For example, where cirrhosis related mortality improved in Maryland, beginning in 2009, all cause mortality improved in Maryland until 2010, then plateaued.

Supplementary table 8 shows trends in cirrhosis related mortality compared with deaths due to infections, neoplasia, cardiovascular disease, and respiratory diseases to assess for the presence of unmeasured secular trends. All other disease categories were associated with improvements in mortality, whereas mortality due to cirrhosis worsened. Although each category showed improvements, the trends observed for the other causes were not statistically parallel. Each category was associated with continuous (linear) improvement except infections, which began to improve most after 2009.

\section{Discussion}

Cirrhosis and hepatocellular carcinoma are fatal conditions, each with increasing footprints in American 


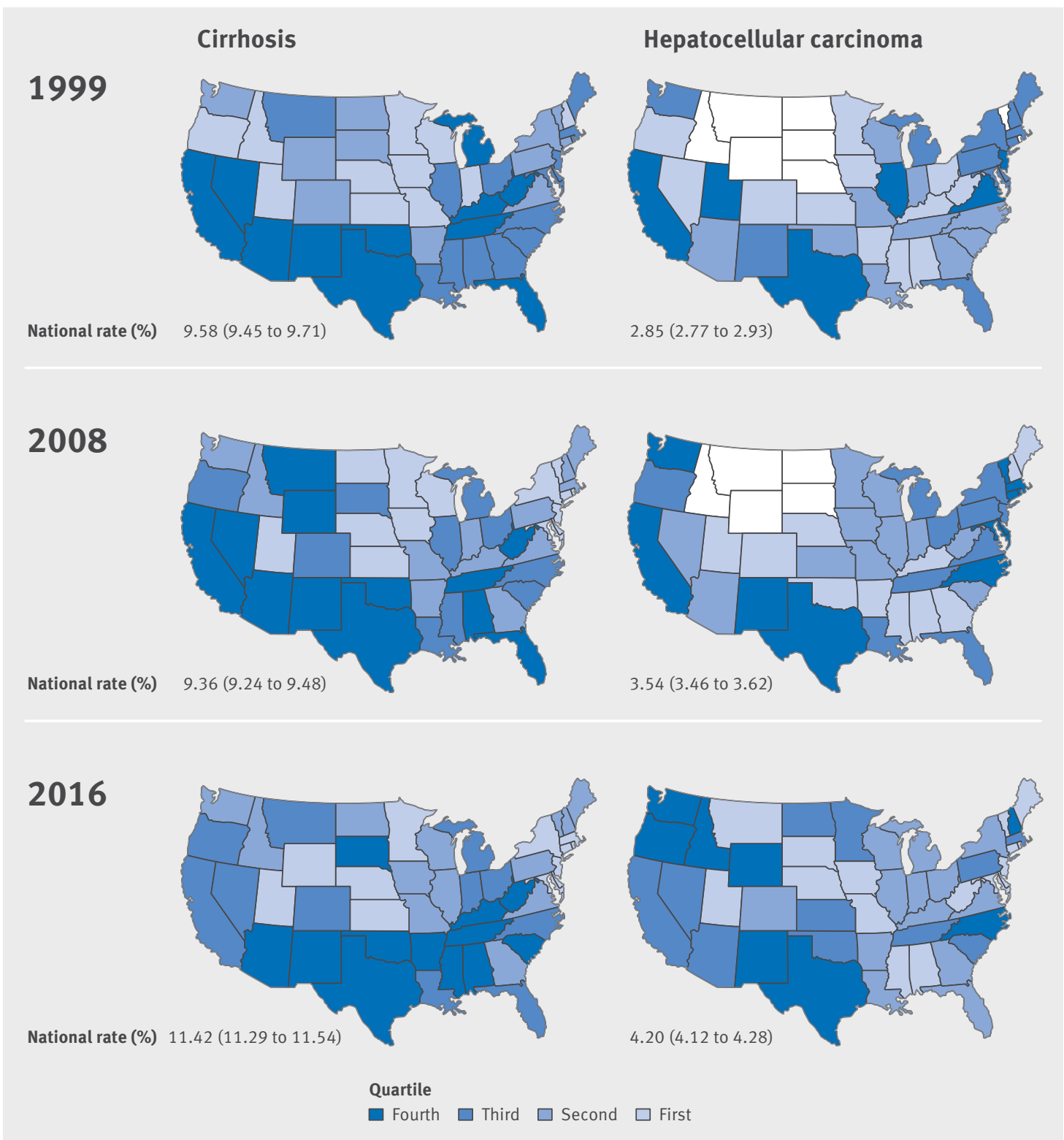

Fig 2 | Age adjusted mortality (per 100000 Americans) attributable to cirrhosis and hepatocellular carcinoma in each state for the first (1999), middle (2008), and last (2016) year of study. States in white imply data that are unreliable or suppressed to protect patient identity

public health. For those with advanced liver disease, death is but one outcome among many, including caregiver burden and disability. The increasing mortality due to cirrhosis and hepatocellular carcinoma speak to the expanding socioeconomic impact of liver disease. Adverse trends in liver related mortality are particularly unfortunate given that in most cases the liver disease is preventable. Understanding the factors associated with mortality due to these conditions will inform how best to allocate resources. In this study, we found that mortality due to cirrhosis has been increasing in the USA since 2009, particularly for young people, white Americans, Native Americans, and Hispanic Americans as well as those living in Kentucky, New Mexico, and Arkansas. Conversely, hepatocellular carcinoma mortality has worsened continuously, save for young people and Asian Americans.

\section{Worsening cirrhosis and hepatocellular carcinoma related mortality}

Mortality due to cirrhosis has been increasing since 2009. One study, in Olmstead county, found unchanged age and sex adjusted death rates due to liver disease from 1979 (25.8/100 000) to $2008(25.7 / 100000) .^{26}$ We extend these data in our analysis, finding increased mortality during 2009-2016 in the context of declining mortality due to other causes such as cardiovascular disease, neoplasia, respiratory disease, and infectious diseases.

\section{Mortality trends by demographics}

Increases in cirrhosis related mortality disproportionately affect young people aged 25-34, white Americans, Native Americans (designated as "American Indians" in the census database), and 

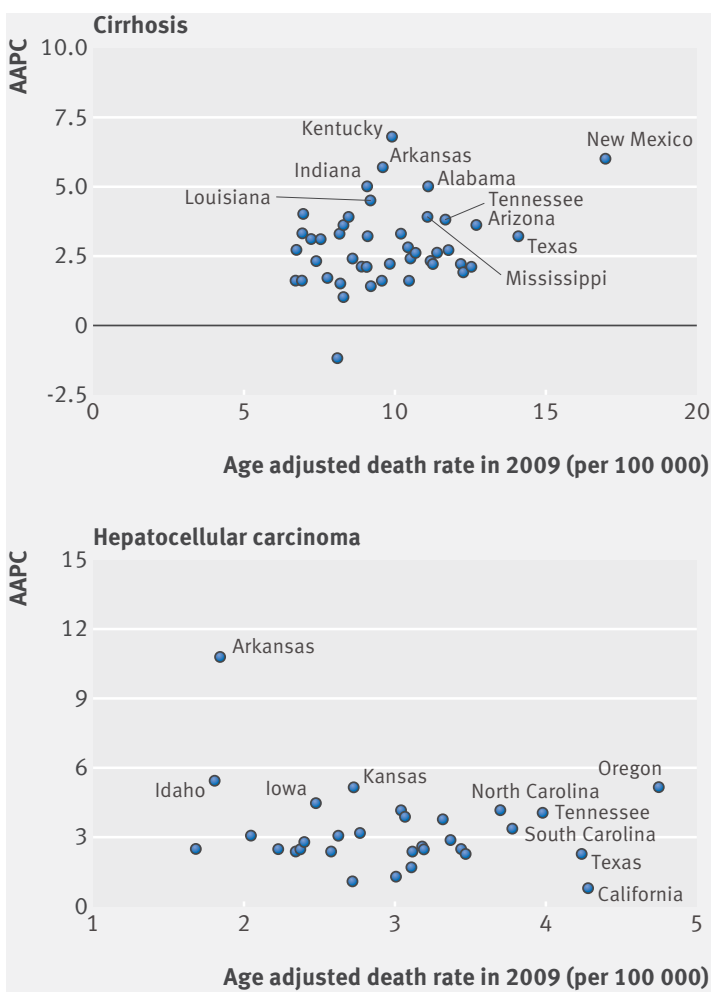

Fig 3 | US states with statistically significant changes in death rates attributable to cirrhosis and hepatocellular carcinoma, 2009-16. AAPC=average annual percentage change

Hispanic Americans. These changes seem to be driven by alcohol related liver disease and alcohol use disorder, which are largely preventable causes of death in this age group. Estimates of deaths due to alcohol related diseases before 2010 show that mortality was concentrated in those aged 65 years or more. ${ }^{27}$ The current study extends such data by showing that, in recent years, the rate of change in mortality is greatest for young people. The impact of these preventable deaths is compounded by their economic impact, measured in decades per person of lost productivity and outsized healthcare costs (as much as twice that of non-alcoholic cirrhosis ${ }^{11}$ ). Conversely, mortality due to hepatocellular carcinoma continues to increase in older Americans while decreasing in younger people and people of Asian race. These trends also parallel those observed for the incidences of hepatocellular carcinoma. $^{12}$ Potential explanations supported by these data include increasing early detection of hepatocellular carcinoma, application of curative or locoregional therapies, and, because hepatitis $\mathrm{B}$ is the principal cause of hepatocellular carcinoma worldwide and among Asian Americans, effectiveness of vaccination programs and the efficacy of antiviral therapy for hepatitis B in preventing the development of hepatocellular carcinoma. ${ }^{28-31}$

\section{Impact of infections on mortality}

Peritonitis and sepsis were the causes of death associated with cirrhosis that had the most consistent and substantial increases over the study period. Patients with cirrhosis are at increased risk of infections owing to impaired immunity and propensity for bacterial translocation from the gut, especially in the setting of portal hypertension. ${ }^{232-34}$ Infections, particularly spontaneous bacterial peritonitis, are a major cause of death in patients with cirrhosis and are major contributors to the observed increase in cirrhosis related mortality in the current study. Proton pump inhibitors, both over-prescribed and associated with spontaneous bacterial peritonitis, as well as increased susceptibility to antibiotic resistant bacterial organisms, might contribute to the observed trends. ${ }^{35}$

\section{State level variations in mortality}

Specific states in the south and west experienced the worst trends for cirrhosis and hepatocellular carcinoma related mortality. Only Maryland showed consistent reductions in mortality due to cirrhosis. Adverse trends in Kentucky, New Mexico, Arizona, and Oregon in particular require further study for explanation. Given that the worsening trends began after 2008, a year marked by the global financial crisis and a subsequent economic recession in the USA, a differential economic impact on specific states may explain some of the results. Since increases in mortality were greatest for young men, these data may dovetail with trends in alcohol misuse, established to predominantly affect younger men; becoming unemployed is linked with alcohol misuse in young men but not older people or women. ${ }^{36}$

\section{Clinical and health policy implications}

Cirrhosis is associated with morbidity and is costly to treat and therefore efforts to prevent progression of all liver diseases are cost effective. ${ }^{14} 153738$ Our data highlight several modifiable sources of mortality. Firstly, young people, particularly Native Americans and white Americans, may benefit from intensified resources to screen for and treat alcohol use disorders. Secondly, quality improvement efforts are needed to optimize the identification and prophylaxis of spontaneous bacterial peritonitis and to decrease the overuse of proton pump inhibitors ${ }^{39}$; additional data are needed to identify the optimal preventive strategies for spontaneous bacterial peritonitis in the era of multidrug resistant organisms. Thirdly, research and outreach are required to understand and contextualize the factors associated with the adverse trends identified in many states. In addition to resources for alcohol related disease, the role of state level policy instruments such as increased taxes on alcohol (which have been linked with decreased alcohol related disease ${ }^{4041}$ ) deserve attention. In this regard, forthcoming data from Scotland will prove instructive. ${ }^{42}$ Having mandated for alcoholic beverages a minimum of $€ 0.50$ (£066; €0.57) per unit price, the impact of this program on Scottish public health should be eagerly awaited by American policy makers. 

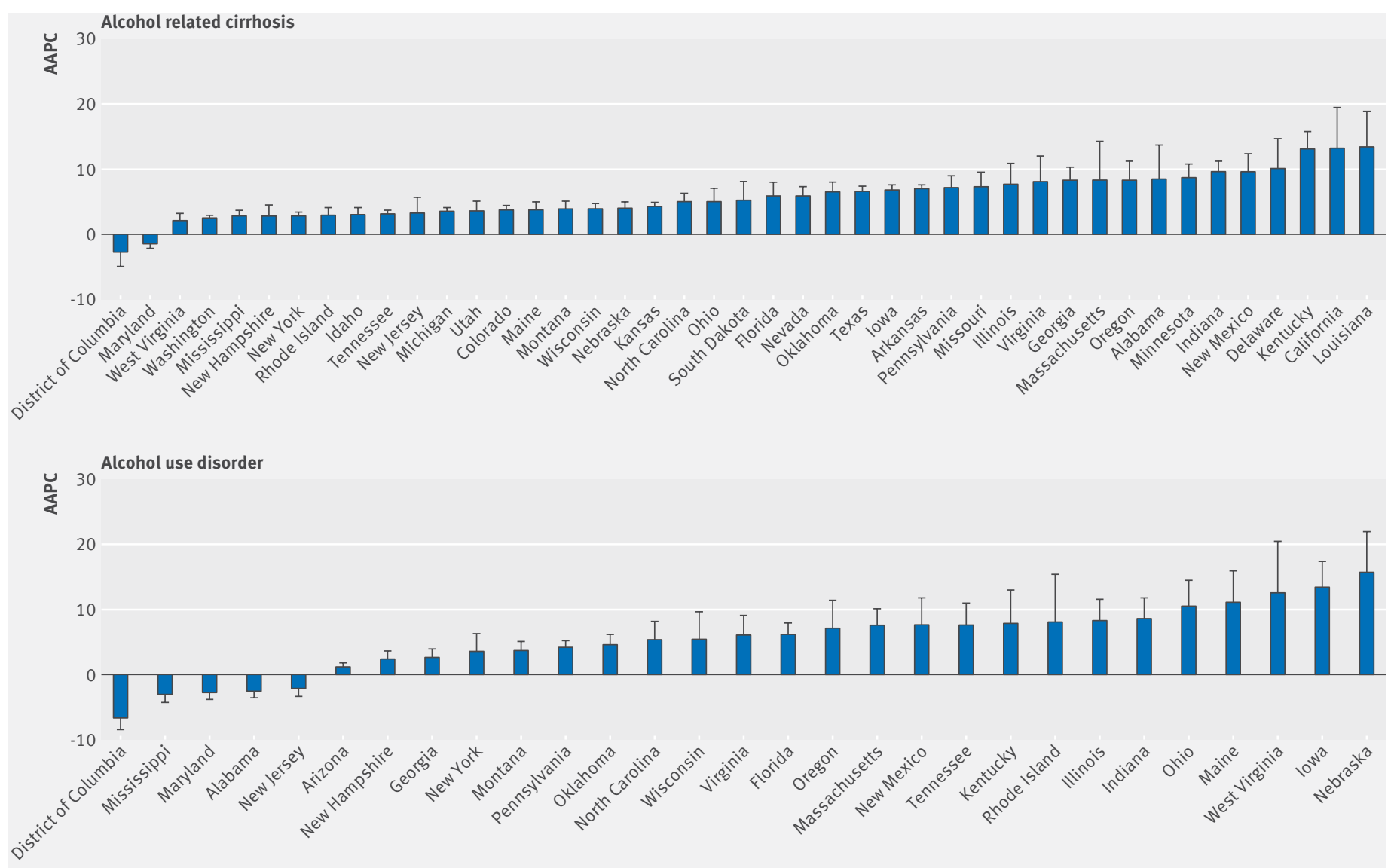

Fig 4 | US states with statistically significant average annual percentage change (AAPC) in mortality due to alcohol related cirrhosis and alcohol use disorder, 2009-16. Whiskers represent $95 \%$ confidence intervals

\section{Contextual factors}

Several things need to be considered in the interpretation of these results. Firstly, these findings are based on data abstracted from death certificates, which may be inaccurate (in up to $15 \%$ of cases $^{43}$ ), and this study does not explicitly validate disease coding with chart review. For this reason we chose the diagnostic codes most specific to cirrhotic complications. Still, sensitivity analyses using a variety of coding algorithms for liver disease confirm consistency of results, and comparisons of our results with other conditions imply independence from secular trends. Secondly, though we have detected worsening mortality since 2009 , the precise reasons for this trend and the geographic heterogeneity in our analysis require further study. For example, we identify the states most at risk, but granular data are needed to determine the root causes, be they trends in healthcare access and insurance, policy (eg, alcohol tax rates or laws), employment, education levels, or the differential changes in the comorbidities (eg, obesity) of a given state's population.

Thirdly, it is unclear how these trends are, or will be, affected by direct active antivirals for hepatitis $\mathrm{C}$ virus. We included three years of data since the approval of direct active antivirals, and the observed trends have remained consistent. Screening for hepatitis C virus is recommended, given the availability of highly efficacious therapy; however, 100s of 1000s of individuals in the USA have undetected hepatitis $C$ virus or do not have access to antiviral therapy. ${ }^{1544}$ At the same time, eradication of hepatitis $C$ virus will prevent the development of cirrhosis and its complications, potentially changing these trends in the next 5-10 years. However, therapy for hepatitis $\mathrm{C}$ viral infection cannot modify the statistically significant trends observed related to alcohol or the expected increase in the burden of non-alcoholic fatty liver disease. ${ }^{8}$

\section{Conclusion}

Specific demographic subgroups and states are disproportionately affected by adverse trends in deaths from cirrhosis and hepatocellular carcinoma. Additionally, patients with cirrhosis are more likely to die from specific secondary causes (ie, infections.) These data underscore gaps in care and opportunities for prevention.

Contributors: Both authors conceived the study, acquired and analyzed the data, and wrote the manuscript. EBT is the guarantor.

Funding: EBT receives funding from the National Institutes of Health (NIH) through the Michigan Institute for Clinical and Health Research (KL2TR002241). The content is solely the responsibility of the authors and does not necessarily represent the official views of the NIH. 
Competing interests: All authors have completed the ICMJE uniform disclosure form at www.icmje.org/coi disclosure.pdf and declare: no support from any organization for the submitted work for NDP, whereas EBT receives funding from the National Institutes of Health (NIH) through the Michigan Institute for Clinical and Health Research (KL2TR002241); no financial relationships with any organizations that might have an interest in the submitted work in the previous three years; outside the current work, EBT has received grants from Valeant and from Gilead and personal fees from Novartis, and NDP has received personal fees from Bristol Myers Squibb, Bayer, and Eisai, and grants from Bayer and TARGET Pharmaceuticals. The corresponding author attests that all listed authors meet authorship criteria and that no others meeting the criteria have been omitted.

Ethical approval: Not required as this is a publically available dataset of deidentified data.

Data sharing: Contact the corresponding author at etapper@umich. edu for any inquiries regarding data or analytical code.

Transparency: The lead author (EBT) affirms that the manuscript is a honest, accurate, and transparent account of the study bring reported; that no important aspects of the study have been omitted

This is an Open Access article distributed in accordance with the Creative Commons Attribution Non Commercial (CC BY-NC 4.0) license, which permits others to distribute, remix, adapt, build upon this work non-commercially, and license their derivative works on different terms, provided the original work is properly cited and the use is noncommercial. See: http://creativecommons.org/licenses/by-nc/4.0/.

1 Schuppan D, Afdhal NH. Liver cirrhosis. Lancet 2008;371:838-51. doi:10.1016/S0140-6736(08)60383-9

2 Tapper EB, Finkelstein D, Mittleman MA, Piatkowski G, Lai M. Standard assessments of frailty are validated predictors of mortality in hospitalized patients with cirrhosis. Hepatology 2015;62:584-90. doi:10.1002/hep.27830

3 Bajaj JS, Wade JB, Gibson DP, et al. The multi-dimensional burden of cirrhosis and hepatic encephalopathy on patients and caregivers. Am J Gastroenterol 2011;106:1646-53. doi:10.1038/ ajg.2011.157

4 Patel AA, Walling AM, Ricks-Oddie J, May FP, Saab S, Wenger N. Palliative Care and Health Care Utilization for Patients With End-Stage Liver Disease at the End of Life. Clin Gastroenterol Hepatol 2017:15:1612-19. doi:10.1016/j.cgh.2017.01.030

5 Beste LA, Leipertz SL, Green PK, Dominitz JA, Ross D, loannou GN. Trends in burden of cirrhosis and hepatocellular carcinoma by underlying liver disease in US veterans, 2001-2013. Gastroenterology 2015:149:1471-1482.e5. doi:10.1053/i. gastro.2015.07.056

6 D'Amico G, Garcia-Tsao G, Pagliaro L. Natural history and prognostic indicators of survival in cirrhosis: a systematic review of 118 studies[published Online First: 2005/11/22]. Hepatol 2006;44:217-31. doi:10.1016/j.jhep.2005.10.013

7 Moon AM, Green PK, Berry K, loannou GN. Transformation of hepatitis $C$ antiviral treatment in a national healthcare system following the introduction of direct antiviral agents. Aliment Pharmacol Ther 2017;45:1201-12. doi:10.1111/apt.14021

8 Estes C, Razavi H, Loomba R, Younossi Z, Sanyal A. Modeling the epidemic of nonalcoholic fatty liver disease demonstrates an exponential increase in burden of disease. Hepatology 2018:67:123-33. doi:10.1002/hep.29466

9 Parikh ND, Marrero WJ, Wang J, et al. Projected increase in obesity and non-alcoholic-steatohepatitis-related liver transplantation waitlist additions in the United States. [published Online First: 2017/8/17]. Hepatology 2017.

10 Younossi ZM, Stepanova M, Afendy M, et al. Changes in the prevalence of the most common causes of chronic liver diseases in the United States from 1988 to 2008. Clin Gastroenterol Hepatol 2011;9:524-530.e1. doi:10.1016/j.cgh.2011.03.020

11 Mellinger JL, Shedden K, Winder GS, et al. The high burden of alcoholic cirrhosis in privately insured persons in the United States. Hepatology 2018. doi:10.1002/hep.29887

12 White DL, Thrift AP, Kanwal F, Davila J, El-Serag HB. Incidence of hepatocellular carcinoma in all 50 United States, from 2000 through 2012. Gastroenterology 2017:152:812-820.e5. doi:10.1053/j. gastro.2016.11.020

13 Tapper EB, Catana AM, Sethi N, et al. Direct costs of care for hepatocellular carcinoma in patients with hepatitis $\mathrm{C}$ cirrhosis. Cancer 2016:122:852-8. doi:10.1002/cncr.29855

14 Tapper EB, Sengupta N, Hunink MG, Afdhal NH, Lai M. Cost-effective evaluation of nonalcoholic fatty liver disease with NAFLD fibrosis score and vibration controlled transient elastography. Am J Gastroenterol 2015;110:1298-304. doi:10.1038/ajg.2015.241
15 Rein DB, Smith BD, Wittenborn JS, et al. The cost-effectiveness of birth-cohort screening for hepatitis $\mathrm{C}$ antibody in U.S. primary care settings. Ann Intern Med 2012;156:263-70. doi:10.7326/00034819-156-4-201202210-00378

16 White DL, Thrift AP, Kanwal F, Davila J, El-Serag HB. Incidence of Hepatocellular Carcinoma in All 50 United States, From 2000 Through 2012. Gastroenterology 2017;152:812-820.e5. doi:10.1053/j.gastro.2016.11.020

17 Aghaei I, Saeedi Saravi SS, Ghotbi Ravandi S, et al. Evaluation of prepulse inhibition and memory impairments at early stage of cirrhosis may be considered as a diagnostic index for minimal hepatic encephalopathy[published Online First: 2017/01/26]. Physiol Behav 2017:173:87-94. doi:10.1016/i.physbeh 2017.01.033

18 Anderson RN, Rosenberg HM. Age standardization of death rates: implementation of the year 2000 standard. Natl Vital Stat Rep 1998; 47:1-16, 20

19 Allen AM, Therneau TM, Larson J), et al. Nonalcoholic Fatty Liver Disease Incidence and Impact on Metabolic Burden and Death: a 20 Year-Community Study. Hepatology 2018; 67:1726-36. doi:10.1002/hep.29546

20 Kim HJ, Fay MP, Feuer EJ, Midthune DN. Permutation tests for joinpoint regression with applications to cancer rates. Stat Med 2000;19:33551. doi:10.1002/(SICI)1097-0258(20000215)19:3<335::AIDSIM336)3.0.CO;2-Z

21 Hudson DJ. Fitting segmented curves whose join points have to be estimated. J Am Stat Assoc 1966;61:1097-129. doi:10.1080/0162 1459.1966.10482198

22 Lerman P. Fitting segmented regression models by grid search. Appl Stat 1980;29:77-84. doi:10.2307/2346413

$23 \mathrm{Kim} \mathrm{HJ}$, Luo J, Chen HS, et al. Improved confidence interval for average annual percent change in trend analysis. Stat Med 2017;36:3059-74. doi:10.1002/sim.7344

24 Clegg LX, Hankey BF, Tiwari R, Feuer EJ, Edwards BK. Estimating average annual per cent change in trend analysis. Stat Med 2009;28:3670-82. doi:10.1002/sim.3733

25 Kim HJ, Fay MP, Yu B, Barrett MJ, Feuer El. Comparability of segmented line regression models. Biometrics 2004;60:1005-14. doi:10.1111/ j.0006-341X.2004.00256.x

26 Asrani SK, Larson JJ, Yawn B, Therneau TM, Kim WR. Underestimation of liver-related mortality in the United States. Gastroenterology 2013;145:375-82.e1, 2. doi:10.1053/j. gastro.2013.04.005

27 Rehm J, Samokhvalov AV, Shield KD. Global burden of alcoholic liver diseases. / Hepatol 2013;59:160-8. doi:10.1016/j. jhep.2013.03.007

28 Chen C-I, Yang H-I, Su J, et al, REVEAL-HBV Study Group. Risk of hepatocellular carcinoma across a biological gradient of serum hepatitis B virus DNA level. JAMA 2006;295:65-73. doi:10.1001/ jama.295.1.65

29 Altekruse SF, McGlynn KA, Reichman ME. Hepatocellular carcinoma incidence, mortality, and survival trends in the United States from 1975 to 2005. / Clin Oncol 2009:27:1485-91. doi:10.1200/ ICO.2008.20.7753

30 Altekruse SF, Henley SJ, Cucinelli JE, McGlynn KA. Changing hepatocellular carcinoma incidence and liver cancer mortality rates in the United States. Am I Gastroenterol 2014:109:542-53. doi:10.1038/ajg.2014.11

31 Ulahannan SV, Duffy AG, McNeel TS, et al. Earlier presentation and application of curative treatments in hepatocellular carcinoma. Hepatology 2014:60:1637-44. doi:10.1002/hep.27288

32 Tapper EB, Risech-Neyman Y, Sengupta N. Psychoactive medications increase the risk of falls and fall-related injuries in hospitalized patients with cirrhosis. Clin Gastroenterol Hepatol 2015;13:1670-5. doi:10.1016/j.cgh.2015.03.019

33 Lai JC, Feng S, Terrault NA, Lizaola B, Hayssen H, Covinsky K. Frailty predicts waitlist mortality in liver transplant candidates. Am I Transplant 2014:14:1870-9. doi:10.1111/ajt.12762

34 Bajaj IS, O'Leary JG, Tandon P, et al. Hepatic Encephalopathy Is Associated With Mortality in Patients With Cirrhosis Independent of Other Extrahepatic Organ Failures. Clin Gastroenterol Hepatol 2017;15:565-574.e4.https://www.ncbi.nlm.nih. gov/entrez/query.fcgi?cmd=Retrieve\&db=PubMed\&list_ uids=27720916\&dopt=Abstract10.1016/i.cgh.2016.09.157

35 European Association for the Study of the Liver. EASL Clinical Practice Guidelines for the management of patients with decompensated cirrhosis. J Hepatol 2018:50168-8278(18)31966-4.

36 Temple MT, Fillmore KM, Hartka E, Johnstone B, Leino EV, Motoyosh M. A meta-analysis of change in marital and employment status as predictors of alcohol consumption on a typical occasion. $\mathrm{Br}$ J Addict 1991:86:1269-81 doi:10.1111/i1360-0443.1991 tb01703x

37 Leidner AJ, Chesson HW, Spradling PR, Holmberg SD. Assessing the effect of potential reductions in non-hepatic mortality on the estimated cost-effectiveness of hepatitis C treatment in early stages of liver disease. Appl Health Econ Health Policy 2017;15:65-74. doi:10.1007/s40258-016-0261-2 
38 Veldhuijzen IK, Toy M, Hahné SJ, et al. Screening and early treatment of migrants for chronic hepatitis $B$ virus infection is cost-effective. Gastroenterology 2010;138:522-30. doi:10.1053/j. gastro.2009.10.039

39 Tapper EB. Building effective quality improvement programs for live disease: a systematic review of quality improvement initiatives. Clin Gastroenterol Hepatol 2016;14:1256-1265.e3. doi:10.1016/j. cgh.2016.04.020

40 Ponicki WR, Gruenewald PJ. The impact of alcohol taxation on liver cirrhosis mortality. J Stud Alcohol 2006;67:934-8. doi:10.15288/ jsa.2006.67.934

41 Xuan Z, Chaloupka FJ, Blanchette JG, et al. The relationship between alcohol taxes and binge drinking: evaluating new tax measures incorporating multiple tax and beverage types. Addiction 2015:110:441-50. doi:10.1111/add.12818
42 Scottish Government. Minimum Unit Pricing. 2018. (Accessed July 6, 2018, at http://www.gov.scot/Topics/Health/Services/Alcohol/ minimum-pricing

43 German RR, Fink AK, Heron M, et al, Accuracy of Cancer Mortality Study Group. The accuracy of cancer mortality statistics based on death certificates in the United States. Cancer Epidemiol 2011;35:126-31. doi:10.1016/j. canep.2010.09.005

44 Chhatwal J, Wang X, Ayer T, et al. Hepatitis C Disease Burden in the United States in the era of oral direct-acting antivirals. Hepatology 2016;64:1442-50. doi:10.1002/ hep. 28571

Supplemental information: additional material 